\title{
Analysis on Development Efficiency of Rural E-commerce Based on DEA in Sichuan Province
}

\author{
Yi Zhang ${ }^{1, \mathrm{a}}$, Ruiqi Deng ${ }^{2, \mathrm{~b}}$, Jiaying Chen ${ }^{* 3, \mathrm{c}}$, Zuyu Yi ${ }^{* 4, \mathrm{~d}}$ \\ ${ }^{1}$ Sichuan Agricultural University, Dujiangyan, Chengdu, Sichuan, China \\ ${ }^{2}$ Sichuan Agricultural University, Dujiangyan, Chengdu, Sichuan, China \\ ${ }^{3}$ Sichuan Agricultural University, Dujiangyan, Chengdu, Sichuan, China \\ ${ }^{4}$ Sichuan Agricultural University, Dujiangyan, Chengdu, Sichuan, China
}

\begin{abstract}
Under the background of the new era, the development efficiency of rural e-commerce is closely related to the context of rural revitalization. As a big agricultural province in China, Sichuan Province has actively developed rural e-commerce in recent years. Based on the two-year field survey data, government website data, select talent reserve, logistics construction, policy support as input indicators, e-commerce development level, poverty alleviation effect as output indicators, the DEA analysis method is used to analyze the problems of regional development of rural e-commerce in Sichuan, such as imbalance, unreasonable input resources, etc. Based on this, this paper puts forward some suggestions on the development of rural ecommerce talents, the matching of capital injection and demand, and the orientation of rural e-commerce in order to provide reference for the development of rural e-commerce in Sichuan counties.
\end{abstract}

\section{Introduction}

Since the Ministry of Commerce and the Ministry of Finance jointly launched the "e-commerce into rural areas" project in 2014, rural e-commerce has become a "tuyere" in the development of rural economy and a carriage to stimulate rural revitalization. As a big agricultural province, Sichuan Province has actively developed rural e-commerce in recent years. By 2019, there were 94 national "e-commerce into rural" demonstration counties in Sichuan Province, accounting for 11 percent of the country, ranking among the top in the country.

Scientific and efficient rural e-commerce development meets the practical needs. However, at present, there are more redundant and insufficient investment in the field of rural e-commerce, and a large number of funds and policies to help enter the countryside have a low actual efficiency and low degree of utilization. Uneven resource investment and low development efficiency have become important obstacles to the development of rural ecommerce.

At present, there is little analysis on the input-output status and development efficiency of rural e-commerce. In the existing research literature, business model and logistics industry are the main research, and the corresponding development degree comparison and evaluation system is lacking. Although there are also problems related to the development of regional rural ecommerce, most of them are qualitative analysis and lack of necessary quantitative research. At the same time, there are significant differences in the efficiency analysis of rural e-commerce development in different regions due to the large regional differences. Some quantitative studies mainly focus on the national perspective and fail to analyze the development of rural e-commerce in Sichuan.

Therefore, based on two years of field investigation and collection of data and county bulletins, government websites to disclose data, using DEA( data envelopment analysis), this paper analyzes the development efficiency of rural e-commerce in all counties of Sichuan province, in order to provide a reference for the development of rural e-commerce in all counties of sichuan province.

\section{Model selection and data sources}

\subsection{Model selection analysis}

Data envelopment analysis (abbreviated as DEA) is selected to study the development efficiency of rural ecommerce in different counties and districts of Sichuan Province. DEA is a special tool for evaluating the relative effectiveness of the same type of organization with multiple inputs and outputs based on mathematical programming. There are many differences in the development of different poor counties in Sichuan Province. This paper selects the input-oriented model of the BCC model optimized on the CCR model, which optimizes the fixed reward hypothesis to variable scale reward. Technical efficiency is decomposed into scale efficiency and pure technical efficiency[1]. 


\subsubsection{DEA principles}

The principle of DEA, data envelopment analysis is to determine the relatively effective production front surface by keeping the input or output of the decision unit (Decision Making Unit, DMU) unchanged, and to project each DMU to the DEA production front surface by mathematical programming method. The relative effectiveness is evaluated by comparing the degree of deviation from the front surface. When measuring the development efficiency of rural e-commerce in a district and county, we need to consider many factors at the same time, that is, including multiple input and output indicators at the same time. However, DEA has obvious advantages in dealing with the efficiency of the same type of departments with multi-input and multi-output indicators.

\subsubsection{DEA function}

DEA is not only suitable for evaluating the efficiency of decision-making departments with complex production relations, but also for difference analysis, sensitivity analysis and efficiency analysis. It can effectively reflect the resource allocation in each system and perform quantitative analysis.

\subsubsection{DEA Model Mathematical Expression}

Suppose there are $\mathrm{w}$ decision units, each with $\mathrm{n}$ inputs and $p$ outputs, then the operating efficiency under the inputoriented BCC model is[2]:

$$
\begin{aligned}
& \text { Maxm } m_{k}=\sum_{r=1}^{p} u_{k} y_{r k}-U_{k} \\
& \quad \text { Among them }=1 \sum_{r=1}^{p} u_{k} y_{r k} \\
& \sum_{r=1}^{p} u_{k} y_{r k}-\sum_{i=1}^{n} v_{i} x_{i k}-U_{k} \leq 0 \\
& \quad u_{r} \xi>v_{i} \xi>\geq 0 ; \geq 0 ; \mathrm{i}=1,2,3,4 \ldots \mathrm{p} ; \mathrm{ri}=1,2,3,4 \ldots \mathrm{p} ; \\
& \mathrm{ki}=1,2,3,4 \ldots \mathrm{w}
\end{aligned}
$$

Table 1 DEA Introduction to Model Mathematical Variables

DEA model mathematical variable interpretation

\begin{tabular}{|c|c|}
\hline Mathematical Expression & Interpretation \\
\hline $\mathbf{x}_{\mathbf{i k}}$ & i inputs for the k decision module \\
\hline $\mathbf{y}_{\mathbf{r k}}$ & Output $\mathrm{r}$ for the $\mathrm{k}$ decision module \\
\hline $\mathrm{v}_{i}, \mathrm{u}_{r}$ & Weighted factor for $\mathrm{i}$ inputs and $\mathrm{r}$ inputs that may be outputs \\
\hline$\Xi$ & Any integer set, guaranteed \\
& $\begin{array}{c}\text { All inputs and outputs } \\
\text { Get a positive weight }\end{array}$ \\
\hline$U_{k}$ & Scale reward indicators \\
\hline
\end{tabular}

\subsection{Data sources}

This paper selects the national "e-commerce into rural" demonstration county as the object of study. The national "e-commerce into rural areas" demonstration county is a state-supported e-commerce development project in poor counties, and its acceptance has national standards. According to the requirements of the project country, each county should set up its own big data center of ecommerce, take the month as the foundation unit, statistics the real-time development process of rural e-commerce, and report the relevant data to the Department of Commerce of Sichuan Province on a monthly basis. Each county will also put the data in its government open website for appropriate publicity. Therefore, the data of this paper are derived from the two-year field survey of the author's team (the data obtained from the field application to the government department), the disclosure data of the relevant government affairs public website of each county and the county bulletin. The input data of rural e-commerce in each county shall be based on the relevant input after the start of the "e-commerce into rural" demonstration county project, and the output data shall be based on the completion of the national acceptance of the project.

\section{Selection of variables}

This paper combines the relevant references with the reference index of the actual work of rural e-commerce development, and needs to consider the availability and analysis of the data. Finally, the following five variables are selected:

Input variables: talent reserve, logistics construction, policy support

Output variables: e-commerce development level, poverty alleviation effect 
Table 2 Selection of Variables in the Efficiency Analysis of Rural E-commerce Discovery in Sichuan Province

\begin{tabular}{|c|c|c|}
\hline Classification of variables & Variable name & Variable interpretation \\
\hline \multirow{2}{*}{ Output } & Poverty alleviation effects & Number of persons in poverty \\
\cline { 2 - 3 } & Development Level of E-commerce & Rural e-commerce individuals \\
\hline \multirow{3}{*}{ Inputs } & Talent reserve & Number of e-commerce trainees \\
\cline { 2 - 3 } & Logistics construction & Logistics sites (townships) \\
\cline { 2 - 3 } & Policy support & Investments (central funds) \\
\hline
\end{tabular}

\subsection{Input variables}

\subsubsection{Talent reserve}

Talent reserve is the source of rural e-commerce development, many scholars at home and abroad think that talent reserve plays an important role in the development of rural e-commerce.[3]Zhang Wenhui and Hu Bei pointed out that rural e-commerce practitioners or entrepreneurs need to learn business knowledge, network technology and e-commerce application skills[4]. Zhou Haiqin believes that the key element in the development of rural e-commerce is the exemplary role of rural e-commerce pioneers[5].Fu Xiaofeng believes that it is necessary to improve farmers' knowledge of the Internet and vigorously train rural e-commerce talents ${ }^{[6]}$.Therefore, comprehensive scholars have a point of view, this paper will be talent reserve as input variables into the model. In recent years, the domestic way to improve the rural ecommerce talent reserve is to carry out agricultural and commercial training, so this paper selects the number of ecommerce training to measure the variable of talent reserve.

\subsubsection{Logistics construction}

Logistics construction is the basis of e-commerce development, express logistics can solve the problem of space limitation. E-commerce enables the rapid, efficient and low-cost transmission of information through the Internet, but as a physical object, as the actual commodity traded in e-commerce, especially the agricultural (auxiliary) products, it must rely on logistics express delivery to transmit the whole transaction completely. Therefore, logistics construction is an essential part of ecommerce, and the situation of logistics construction greatly affects the development of regional e-commerce. The object of this paper is rural e-commerce. Compared with the city, the logistics construction in rural areas has a slow start time and slow progress, which greatly limits the development of e-commerce in rural areas. Therefore, the development of rural e-commerce must pay attention to its logistics construction, so this paper takes the logistics construction as the input variable, and evaluates it by observing the township logistics stations.

\subsubsection{Policy support}

The development of a region and an industry can not be separated from the support of government policies, including the formulation of relevant policies and the implementation of policies. Some scholars believe that industrial policy, as the main tool of government support, is the key factor affecting the effectiveness of industrial policy[7]. China's rural e-commerce is generally in the development stage, its policy support greatly encourages / restricts the local rural e-commerce development process. The implementation of the "e-commerce into rural areas" project will start, the central government will allocate a large amount of funds to the region, the local government, enterprises will also be combined with their own situation according to the percentage of additional funds, but the main impact of regional project development is still the central funding part. There is no unified statistics on the additional funds in each region, so this paper selects the central fund representative policy support variable.

\subsection{Output variables}

\subsubsection{Development Level of E-commerce}

Since 2014, when the Ministry of Commerce and the Ministry of Finance launched the "e-commerce into rural areas" project, after six years of exploration, formed a variety of e-commerce promotion models, such as industrial poverty alleviation, entrepreneurship poverty alleviation, employment poverty alleviation and so on: the government has made a lot of financial and material investment, promulgated a number of preferential policies, vigorously improved infrastructure, and so on. After 1-2 years of cultivation and development, each county has implemented various construction and completed the basic acceptance index. However, the development level of rural e-commerce in each county still presents different levels of difference. Differences are undoubtedly related to different input modes, different input components and different basic conditions. Therefore, by observing the development level of rural e-commerce and using the $\mathrm{E}$ DA model, the input indicators that affect the development level of rural e-commerce are analyzed more pertinently. 


\subsubsection{Poverty alleviation effects}

China strongly supports and invests human and financial resources in rural e-commerce in the critical period of overcoming poverty. It also gives rural e-commerce a historical mission under the background of the era of rural revitalization — teaches people to fish, helps rural people master the tools to become rich, and helps farmers get rid of poverty. Therefore, poverty alleviation effect is an important part of rural e-commerce output. By taking the poverty alleviation effect as the output variable, this paper selects the national acceptance assessment index - the number of people helping the poor to evaluate the poverty alleviation effect.

\section{Metrological analysis}

The comprehensive development efficiency of rural ecommerce in poor counties of Sichuan Province (see Table 3 ) is analyzed as follows:

First, the comprehensive efficiency of rural ecommerce in poor counties of Sichuan Province is 1, there are mainly four counties, namely Zhaohua District, Santai County, Guangan District and Nishui County. Although the efficiency value of Lixian is 1, its representativeness is not strong, so it should not become the main research object. From the point of view of regional distribution, most of these four cities are in the northeast of Sichuan (Zhaohua District belongs to the central part of Sichuan), which indicates that there is an imbalance in the regional development of rural e-commerce in Sichuan.

Table 3 Efficiency of Integrated Development of Rural E-commerce in Poverty-stricken County of Sichuan Province

\begin{tabular}{|c|c|c|c|c|c|}
\hline Poor counties & $\begin{array}{c}\text { Integrated } \\
\text { efficiency }\end{array}$ & $\begin{array}{c}\text { Pure } \\
\text { technical } \\
\text { efficiency }\end{array}$ & $\begin{array}{c}\text { Scale } \\
\text { efficiency }\end{array}$ & $\begin{array}{c}\text { Marginal } \\
\text { margin }\end{array}$ & Year of selection \\
\hline Bazhou District & 0.455 & 0.653 & 0.696 & Irs & 2017 \\
\hline Zhaohua District & 1.000 & 1.000 & 1.000 & - & 2017 \\
\hline Qingchuan County & 0.885 & 1.000 & 0.885 & irs & 2015 \\
\hline Cangxi County & 0.567 & 0.614 & 0.924 & irs & 2016 \\
\hline Leibo County & 0.437 & 0.673 & 0.649 & irs & 2016 \\
\hline Santai County & 1.000 & 1.000 & 1.000 & - & 2014 \\
\hline Dazhu County & 0.348 & 0.507 & 0.686 & irs & 2017 \\
\hline Xiaojin County & 0.472 & 1.000 & 0.472 & irs & 2016 \\
\hline Jinchuan County & 0.339 & 1.000 & 0.339 & irs & 2017 \\
\hline Songpan County & 0.779 & 1.000 & 0.779 & irs & 2017 \\
\hline Li County & 1.000 & 1.000 & 1.000 & - & 2015 \\
\hline Qu County & 0.648 & 0.841 & 0.770 & irs & 2014 \\
\hline Guang'an District & 1.000 & 1.000 & 1.000 & - & 2016 \\
\hline Nishui County & 1.000 & 1.000 & 1.000 & - & 2016 \\
\hline Luding County & 0.430 & 1.000 & 0.430 & irs & 2017 \\
\hline Litang County & 0.094 & 0.488 & 0.193 & irs & 2017 \\
\hline Yilong County & 0.367 & 0.529 & 0.693 & irs & 2016 \\
\hline
\end{tabular}

Second, Qingchuan County, Xiaojin County, Jinchuan County, Songpan County and Luding County have achieved a pure technical efficiency of 1 , but most of these county areas are located in the marginal areas of Sichuan Province, which are neither the core cities in the province nor the developed cities of electronic commerce of agricultural products. It can be understood that under the condition of scarce resources, the difficulty of using resources effectively has been reduced.

Third, from the perspective of rural e-commerce investment in various poverty-stricken counties, although Luding County, Litang County, Yilong County and other counties have a relatively dominant input, the overall efficiency value has not reached 0.5 , which is consistent with the expected input The result is inconsistent. This can be attributed to the excessively restrictive geographical location. The above counties are all located in the fringe areas of Sichuan Province. The input of Litang County is at the middle and upper reaches of the level, and its efficiency value is only 0.094 , which is a good proof.

Fourth, the average technical efficiency of the poor counties in Sichuan Province is 0.84 , and the scale efficiency is 0.74 . It can be seen that technological innovation is the key bottleneck for the improvement of regional efficiency; among the 17 sample counties, 5 cities have constant returns to scale, and 12 cities Increasing returns to scale indicate that rural e-commerce in Sichuan Province is in a state of continuous development for a certain period of time.

Table 4 Insufficient output/redundancy of input elements (integration of two tables)

\begin{tabular}{l|l|c|c|c|c|c}
\multirow{2}{*}{ Poor counties } & \multicolumn{3}{|c|}{ Output } & \multicolumn{2}{c}{ Inputs } \\
\cline { 2 - 6 } & $\begin{array}{c}\text { Number of } \\
\text { persons in } \\
\text { poverty }\end{array}$ & $\begin{array}{c}\text { Rural e- } \\
\text { commerce } \\
\text { individuals }\end{array}$ & $\begin{array}{c}\text { E-commerce } \\
\text { transactions }\end{array}$ & $\begin{array}{c}\text { Number of e- } \\
\text { commerce } \\
\text { trainees }\end{array}$ & $\begin{array}{c}\text { Logistics sites } \\
\text { (townships) }\end{array}$ & $\begin{array}{c}\text { Investments } \\
\text { (central funds) }\end{array}$ \\
\hline
\end{tabular}




\begin{tabular}{c|c|c|c|c|c|c}
\hline Bazhou District & 0 & 122.231 & 597743881.112 & 4084.795 & 0 & 0 \\
Zhaohua District & 0 & 0 & 0 & 0 & 0 & 0 \\
Qingchuan County & 0 & 0 & 0 & 0 & 0 & 0 \\
Cangxi County & 0 & 243.086 & 0 & 4952.868 & 0 & 0 \\
Leibo County & 681.838 & 0 & 0 & 0 & 0 & 0 \\
Santai County & 0 & 0 & 0 & 0 & 0 & 0 \\
Dazhu County & 0 & 113.136 & 309092139.948 & 3043.029 & 0 & 0 \\
Xiaojin County & 0 & 0 & 0 & 0 & 0 & 0 \\
Jinchuan County & 0 & 0 & 0 & 0 & 0 & 0 \\
Songpan County & 0 & 0 & 0 & 0 & 0 & 0 \\
Li County & 0 & 0 & 0 & 0 & 0 & 0 \\
Qu County & 0 & 269.271 & 230114068.441 & 2861.048 & 9.517 & 0 \\
Guang'an District & 0 & 0 & 0 & 0 & 0 & 0 \\
Nishui County & 0 & 0 & 0 & 0 & 0 & 0 \\
Luding County & 0 & 0 & 0 & 0 & 0 & 0 \\
Litang County & 676.065 & 77.6 & 20353837.359 & 0 & 0 & 77.275 \\
Yilong County & 0 & 0 & 0 & 0 & 81.917 & 0 \\
\hline
\end{tabular}

Insufficient output/redundancy of input elements (see table 4) Analysis below

\subsection{Outputs:}

In most cities and counties, there is no relaxation problem, and the overall output of poverty alleviation is in line with the input elements. In Leibo County and Litang County, the number of poverty alleviation is slack because the two counties are located in the southwest edge of Sichuan, and the development time of national e-commerce projects into rural areas is relatively short, so it is difficult to have a direct effect on such long-term projects as poverty alleviation projects, so the problem of relaxation is produced.

However, in Bazhou, Dazhu, Quxian and Litang counties, these cities and counties are located in northern Sichuan, restricted by traffic and economic development, and the development level and comprehensive efficiency of rural e-commerce are low, which makes the output end appear relaxation problem.

\subsection{Inputs:}

The redundancy of investment (central fund) is low, and only Litang County has redundancy in the sample. It shows that all regions of Sichuan Province are still in the stage of sustainable development of rural e-commerce, and the degree of capital demand is high, while Litang County is characterized by redundancy due to the slow start of the project construction, less quantity and less capital demand.

The redundancy of logistics site construction is also low, which indicates that the demand for logistics sites involving villages and towns is very high, and the development space of express logistics industry is large. The redundancy in Quxian and Yilong County is due to the establishment of multiple logistics lines for additional scheduling in the two counties, forming a certain amount of excessive investment of resources.

The redundancy of e-commerce training is low, which indicates that the development of rural e-commerce in various places urgently needs practical talents with basic skills or professional ability, and has a certain gap of grassroots talents. Four cities and counties in Bazhou, Cangxi, Dazhu and Quxian, where the index is redundant, also show that there is unreasonable input resources in the city and county, and too much resources are invested in ecommerce training to cause redundancy and have a negative impact on the output.

\section{Conclusions}

The objective conditions of rural e-commerce are good, but the regional development is different, and the actual output effect is not satisfactory. According to the data, the province's rural e-commerce development counties only Qingshen County presents a profit situation, other counties are generally effective. From the survey data, different regions put e-commerce in different strategic 
positions, such as Qingshen County to build e-commerce as a brand industry, while other regions are still in a state of development. At the same time, it is also sending us a signal to find a suitable rural e-commerce development.

Talent is the driving force of the development of rural e-commerce, and the development of rural e-commerce talents is one of the important and difficult points in the next step of county government enterprises ${ }^{[8]}$. According to the survey data, many counties in Sichuan Province are carrying out the training and introduction of e-commerce talents, not only paying attention to the middle and upper class talents, but also carrying out relevant skills training for farmers on a regular basis. Although it has been encouraging the introduction of talents, there are also a series of problems in talent. How to attract and retain people is a big problem for the government and enterprises. In terms of attractiveness, as a county-level city, the attraction to talents is not as good as that of a large city on the first and second lines; the cultivation of farmers is also based on demand, not a subtle change in thinking. This is also a major problem hindering the development of rural e-commerce.

Brand value and industry building is the future of rural e-commerce, the positioning under the top-level design of the government plays a central role. The brand process of agricultural products meets the needs of the high-end consumer market in the future and is also an important means to realize the construction of rural industrial chain. To this, the government macroscopically to the local localization appears extremely important, the product localization, the market localization, the operation pattern localization... According to the investigation, brand building has gradually risen to the working will of the county government, and has produced varying degrees of effect. Qingshen's bamboo weaving industry has 2.2 billion brand value, Xuyong's special morning tea has 45 billion brand value. Naxi regards liquor industry as its industrial development goal. But the same region is quite different, Naxi and Xuyong relative to the Qingshen, the value positioning is not so accurate, more is to take a variety of products to create together. At the same time, the process of value transformation is very difficult. Although there are hundreds of millions of brand value industries in the local area, the process of transforming it into economic and cultural value is slow, and the value needs to be developed. Therefore, each region can only find its own suitable role to achieve the healthy development of local e-commerce, rural e-commerce, otherwise it can only be imitating.

The development of rural e-commerce is closely related to precision poverty alleviation, but the indirect benefit is greater than the direct benefit. As a major theme of our research, the relationship between rural ecommerce and precision poverty alleviation is a direction of our main investigation, but from the research situation, its effect is not as good as expected. First of all, each county combines rural e-commerce with precision poverty alleviation, and objectively brings benefits directly to poor households; secondly, poor households can only be subjectively marginalized on this train because of their knowledge level, ideology and other reasons. In terms of benefits, the indirect effects of consumption habits, contact networks, living and production habits are greater than the direct effects on the economy; finally, most of the poor households are dynamic poverty caused by uncertain factors. For this situation, it is necessary to operate in a process and gradually solve poverty fundamentally. Rural e-commerce can be a way out, but it also needs local governments to combine reality. A variety of considerations, comprehensive to solve poverty.

Rural e-commerce related technology demand is increasing day by day, but the process is slow, capital demand and injection do not match. Rural e-commerce is not only agricultural products uplink, industrial products to the countryside, but also involves a series of technical industries, such as cold chain logistics, traceability system, big data and so on. These industries accept the benefits brought by rural e-commerce, but feed rural e-commerce more, so that rural areas can develop from all aspects. But in fact, all regions are carrying out rural e-commerce construction, but the process is slow. The main reasons are insufficient funds, insufficient local attraction to market capital, and government capital for public service related construction. To some extent, the development of rural ecommerce has been restricted.

The development of rural e-commerce is in the rising stage, and the overall improvement of knowledge level in the next generation of rural areas will bring about a qualitative improvement.

\section{Acknowledgements}

This paper is supported by the Research Interest Cultivation Project of Sichuan Agricultural University.

\section{References:}

1. Nian Zhiyuan, Li Ning, Lu Jingfu, et al. DEA Analysis on the Input-Output Efficiency of Ecommerce in Agricultural Products Based on J]. Method Statistics and Decision Making ,2019,35(04):111-114.

2. Peng Xiaojia, Zhou Daming. Research on Management Efficiency of Rural E-commerce Model Analysis Based on Consumer Goods Downward Agricultural Technology Economy ,2018(12):111-118.

3. Zhou Dong, Ye Rui. The Influencing Factors of Rural E-commerce Development and the Support of Government — An Empirical Study Based on Fuzzy Set Qualitative Comparative Analysis Rural economy ,2019,000(002):110-116.

4. Zhang Wenhui, Hu Bei. An Empirical Study on the Core Entrepreneurial Power of Entrepreneurs [J].]; and China Science and Technology Forum ,2010,000(005):91195,114...

5. Zhou Haiqin, Zhang Caiming. Analysis of Key Elements for the Development of Rural E-commerce in China [J].] China Information Society ,2012,000(001):17-19.

6. Fu Xiaofeng. [J].] Problems and Countermeasures of 
Rural E-commerce Modern agricultural science and technology ,2010,000(022):45-45.

7. Geng Shu. How the Stage of Development Impacts Industrial Policy: A Case Study Based on China's Solar Energy Industry [J]. Public Administration Review ,2019,000(001):24-50...

8. Zhang Qin, Zhou Zhuo. A Study on the Influencing Factors of the Development of Rural E-commerce in China [J].]1 Logistics Engineering and Management ,2015,37(11):181-183. 